\title{
Effect of varying ratios of dietary calcium and phosphorus on performance, phytate $P$ and mineral retention in Japanese quail (Coturnix cotnurnix Japonica).
}

\begin{abstract}
The effect of different ratios of dietary calcium (Ca) to total phosphorus (tP) on the performances and retention of minerals and phytate phosphorus (pP) by quails were studied using 600 unsexed broiler quails from 1 to 21 days of age. Treatments consist of five corn and soybean meal (CSM) based diets with variable ratios of Ca:tP $(1.96,1.81,1.66,1.53$ and 1.39 ) with four replicate of 30 birds each. Diets contained $3 g$ chromium oxide (Cr2O3)/kg as marker. All ratios of $\mathrm{Ca}$ and $\mathrm{P}$ had no significant effect on feed consumption of birds. There were pronounced differences $(\mathrm{P}<0.05)$ in body weight gain of chicks among treatments at second and third week of age. Improved $(\mathrm{P}<0.05)$ feed conversion ratio was observed at 3 wk of age. Higher ratios of Ca:tP $(1.96$ and 1.81) increased $(\mathrm{P}<0.05)$ the retention of $\mathrm{P}$ compared to other treatments while ratio of 1.96 decreased $(\mathrm{P}<0.05)$ the retention of $\mathrm{Ca}$ and phytate. In conclusion, Ca:tP ratio of 1.81 showed positive effect on most of parameters measured in this study.
\end{abstract}

Keyword: Calcium; Total phosphorus; Phytate P; Broiler quail. 